\title{
Ego-syntonicity in responses to items in the California Psychological Inventory
}

\author{
John A. Johnson \\ Department of Psychology, College Place, Pennsylvania State University, DuBois, PA 15801, USA
}

Available online 21 November 2005

\begin{abstract}
Responding to items on a personality questionnaire can evoke a variety of feelings, from discomfort to indifference to pleasure. Harrison Gough reported that when he wrote items for the California Psychological Inventory (CPI; Gough \& Bradley, 1996), he tried to make the items as ego-syntonic as possible. Ego-syntonic items are those "which a respondent finds congenial, and on which giving an opinion is a rewarding act" (Gough \& Bradley, 1996, p. 10). The present study asked 79 respondents to report how they felt after answering each CPI item. Average affect ratings were above neutral for a majority of items, indicating that Gough had some success in writing ego-syntonic items. Differences in item ego-syntonicity were attributable to other item characteristics. Respondents disliked responding to relatively odd and ambiguous items, items with linguistic negations, and items referring to negative feelings and situations. As predicted by Gough, respondents enjoyed responding to items on the communality scale, items with which most people agree. They also enjoyed items that referred to positive emotions and attitudes and to items indicating extraversion, conscientiousness, low neuroticism, and openness to experience. Highly ego-syntonic items were found to be more valid than less egosyntonic items. Individuals who reported disliking many items were found to be socially anxious. The relation between reports of liking or disliking items, identity, and reputation are discussed, and further research on item response dynamics and validity is proposed.
\end{abstract}

(C) 2005 Elsevier Inc. All rights reserved.

\footnotetext{
is This article is based on an invited talk for the symposium honoring Jack Block Award winner Harrison G. Gough at the sixth annual meeting of the Association for Research in Personality, New Orleans, January $20,2005$. The author thanks Robert Hogan for inviting him to participate in the symposium and Harrison G. Gough for decades of support for CPI-related research. The author's travel to the conference was partially underwritten by a grant from the DuBois Educational Foundation.
}

E-mail address: j5j@psu.edu. 
Keywords: CPI; Item response dynamics; Ego-syntonicity

\section{Introduction}

The research described in this article investigates a property of personality items called egosyntonicity. Ego-syntonic items are those "which a respondent finds congenial, and on which giving an opinion is a rewarding act ... people experience a certain sense of satisfaction ... a small surge of positive affect ... answering 'true' [to an ego-syntonic item] (Gough \& Bradley, 1996, p. 10). The current research addresses the following questions. What kinds of items do respondents dislike/enjoy responding to? What kinds of people dislike/enjoy responding to CPI items? And how is liking/enjoying related to items' abilities to predict relevant criteria?

Historically, asking questions about the psychological experiences of persons responding to personality inventory items has been regarded as inappropriate and unnecessary. One source of this attitude is the classic article by Meehl (1945), who claimed that the profession's understanding of mental dynamics was not advanced enough to consider what is going on in the mind of a person who is responding to a personality item. Meehl's thinking was likely influenced in part by his training as a Freudian analyst (Meehl, 1978). According to Freud, the true causes of our behavior are often hidden in the unconscious, which suggests that asking people to report on their mental processes while responding to items would be unlikely to reveal the actual dynamics underlying those responses. The behaviorist Zeitgeist during the 1940s may also have contributed to Meehl's proposal that we ignore what might be occurring in peoples' heads while responding to personality items. Meehl's $(1945, \mathrm{p}$. 297) proposition was that we treat an item response as "an intrinsically interesting and significant bit of verbal behavior, the non-test correlates of which must be discovered by empirical means" (see also Buchwald, 1961.)

Meehl's depiction of an item response as a "bit of verbal behavior" whose meaning "must be discovered by empirical means" exemplifies the attitude of dustbowl empiricism at the University of Minnesota, where Harrison Gough received his Ph.D. degree in 1949. In fact, Gough modeled the California Psychological Inventory (CPI; Gough \& Bradley, 1996) after the MMPI, using the empirical method of scale construction for many CPI scales. In steps three and four of his four-step procedure for analyzing test scores, Gough $(1965,1987)$ maintained that to explicate the meaning of item responses we must examine the empirical correlates of test scores.

Even though the Minnesotan test authors acknowledged that they could not predict the cognitive and motivational dynamics underlying item responses, this did not stop them from considering, as they authored items, what processes might be occurring. Gough says the following about the authoring process:

"In writing and assembling items for the MMPI, Hathaway and McKinley made a conscious effort to include those that were easy to read, contained only frequently used and readily understood words, and were expressed in everyday idioms and phraseology. The more that these objectives were realized, the greater the possibility that respondents would answer with well-rehearsed and well-established personal reactions. In writing new items for the CPI, these same guidelines were adopted. The relatively simple language of the inventory, in other words, is a matter of policy and not just a happenstance occurrence" (Gough \& Bradley, 1996, p. 10 emphasis added). 
The phrase "well-rehearsed and well-established personal reactions" refers to the cognitive and emotional processes underlying responses to items. My own research program indicates that test authors who correctly anticipate psychological processes are better able to write items whose responses will correlate in expected ways with non-test criteria (Johnson, 1981, 1997a, 2004).

A particularly significant type of "well-established personal reaction" Gough anticipated in respondents was the delight they would experience in expressing certain opinions on a personality inventory. Items that allow for pleasurable expression he called ego-syntonic (Gough, 1987; Gough \& Bradley, 1996). Presumably ego-syntonic items have a positive impact on the assessment process because they get at an aspect of identity deemed especially important or significant to the respondent. Research has shown that a person who likes a behavioral component of his or her identity "is most ready to extend this behavior into a situation calling for its manifestation" (Gruba-McCallister \& Rychlak, 1981, p. 503) and that self-reported trait relevance moderates agreement between self- and peer-assessment of personality (Zuckerman, Bernieri, Koestner, \& Rosenthal, 1989). Whereas the research just cited investigated the how respondents felt about the trait dimension being assessed, the research described in the present article focuses on affect at the level of item responses.

The current study addresses the following questions. First, was Gough successful in writing ego-syntonic items for the CPI? This question is answered by asking respondents to rate their affect on a three-point scale (disliked, neutral, and enjoyed) after responding to each CPI item and examining the distribution of mean ratings across items. Second, what kinds of items are found to be the most ego-syntonic? This question is answered by culling and examining the most liked and disliked items, comparing average ratings across scales, and correlating ratings with item characteristics gathered in a previous study (Johnson, 2004). Finally, what kind of person generally likes or dislikes responding to CPI items? This question is answered by counting the number of items disliked or liked by each person and correlating these two values with the standard CPI folk concept scales.

\section{Method}

\subsection{Participants}

Ninety-three university students received extra credit in an introductory psychology course for participating in the study. The task given to the participants was more arduous than simply responding "True" or "False" to the items as in standard instructions, so it was expected that some participants would respond quickly and inattentively simply to receive the extra credit. The CPI communality $(\mathrm{Cm})$ scale was designed to detect such inattentive responding, and Gough (1987) recommends treating Cm scores of 27 or below with caution. Eliminating participants with $\mathrm{Cm}$ scores of 27 or below reduced the sample to 79 (57 females and 22 males) used in all analyses.

\subsection{Materials and procedure}

Participants were given a booklet for the 462-item version of the California Psychological Inventory (CPI-462; Gough, 1987) and directed to a Web site where they were instructed to rate where they thought they stood on the 20 standard folk concept scales of the CPI. These self-ratings were gathered for a separate study and will not be discussed 
further. Participants then followed a link to a web-based "answer sheet" and given the following instructions:

Directions from the cover of the CPI booklet, modified for answering on this web form: The CPI contains a series of statements. Read each one, decide how you feel about it, and then click the circle under either true or false. If you agree with a statement, or feel that it is true about you, answer TRUE. If you disagree with a statement, or feel that it is not true about you, answer FALSE.

In marking your answers on this web form, make sure that the number of the statement is in the same row as the area where you mark your response. Answering either TRUE or FALSE for every statement, even if you have to guess at some, will improve the accuracy of your results, although you may skip questions you prefer not to answer.

Additional directions: After answering true or false to the item, pause and think about how you felt about answering the item. If responding was neither particularly enjoyable nor unpleasant, choose the neutral response option. If you disliked responding to the item, choose the disliked response option. If you enjoyed responding to the item, choose the enjoyed response option. All items are pre-rated as neutral, so you need to change only the items you especially disliked or enjoyed responding to.

When participants finished responding to and rating the CPI items, their responses were automatically recorded to a file. The "disliked" response was coded as a 1, "neutral," as a 2 , and "enjoyed" as a 3. A program error caused a failure to record the enjoyment rating for CPI item 120, so a value of 2 was assigned to this item for every participant. Mean ego-syntonicity scores for each item were computed by averaging the enjoyment ratings provided by the 79 participants. A frequency curve of the mean ego-syntonicity scores was examined to see how many items fell above or below the neutral value. Average ego-syntonicity values were computed for items on each of the 20 standard CPI folk concept scales to test Gough's prediction that respondents tend to find $\mathrm{Cm}$ items particularly ego-syntonic (Gough \& Bradley, 1996). Items' ego-syntonicity values were correlated with other item variables such as ambiguity, social desirability, content, and validity, using values established by Johnson (2004). Of particular interest is whether ego-syntonic items are more valid (where validity was defined as the Pearson correlation between an item and a peer rating the item is supposed to predict-Johnson, 2004).

The final set of analyses shifted from looking at ego-syntonicity as a property of items to the general tendency to dislike or like responding to items as a property of persons. A disliking score was computed by adding the number of times a person indicated experiencing negative feelings after responding to an item, and a liking score was defined as the number of times a person indicated experiencing positive feelings after responding to an item. These disliking and liking scores were correlated with the 20 standard CPI folk concept scales.

\section{Results}

\subsection{Descriptive statistics}

As a rough check on the reliability of ratings of item ego-syntonicity and on possible sex differences, ego-syntonicity scores were averaged for males and females separately and then 
the males' and females' ratings were correlated. The correlation of $r=.82(p<.01)$ showed that the items most or least enjoyed by males were also rated the same way by females in the sample. Therefore, all subsequent analyses were based on averaged ego-syntonicity scores from males and females combined.

Averaged ego-syntonicity scores ranged from 1.84 to 2.30 (mean $=2.03$ and $S D=.05$ ). The absence of items with either extremely low or extremely high ego-syntonicity scores, coupled with a mean ego-syntonicity score barely above 2 , indicates fairly neutral ego-syntonicity for CPI items as a whole. Nonetheless, there are differences in ego-syntonicity values (see Fig. 1), and more items fell above 2 than below it. Of the 462 items, 240 had average ego-syntonicity values above the absolute neutral point of 2, 57 fell right at 2 , and 165 were below 2 . These findings indicate that Gough was partially successful in writing ego-syntonic items for the CPI.

\subsection{Items with highest and lowest ego-syntonicity}

Items with the highest and lowest average ego-syntonicity values are shown in Table 1. Items with lowest ego-syntonicity seemed to contain content that might seem odd to respondents (e.g., "I like tall women" [1.84]) or referred to negative events or feelings (e.g., "I certainly feel useless at times" [1.90]). Items with the highest ego-syntonicity seemed consistently to reflect positive feelings or attitudes (e.g., "My daily life is full of things that keep me interested" [2.19]). Table 2 shows the average ego-syntonicity value of all items within each of the standard CPI folk concept scales. These average values were all slightly positive, ranging from 2.01 to 2.06. As Gough predicted (Gough \& Bradley, 1996), items on the $\mathrm{Cm}$ scale had the highest average ego-syntonicity value.

\subsection{Correlates of ego-syntonicity}

Table 3 presents correlations between ego-syntonicity and all of the CPI item properties compiled by Johnson (2004). Unsurprisingly, high ego-syntonicity was associated

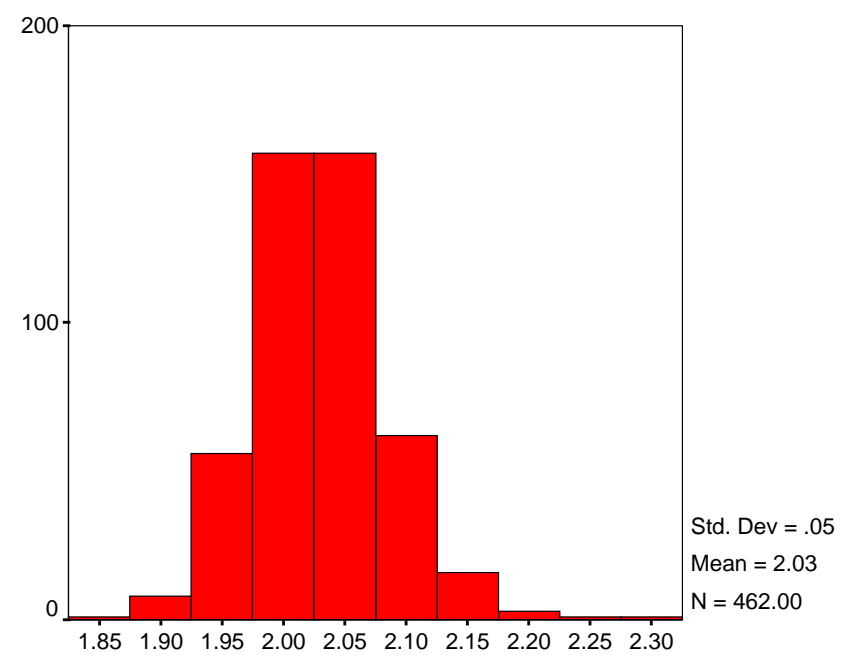

Fig. 1. Frequency distribution of averaged ego-syntonicity values. 
Table 1

CPI items with lowest and highest ego-syntonicity

\begin{tabular}{lll}
\hline CPI item & ES & CPI scale \\
\hline I like tall women & 1.84 & $\mathrm{Cs}$ \\
I think Lincoln was greater than Washington & 1.89 & $\mathrm{Cs}$ \\
When a person "pads" an income tax report so as & 1.90 & $\mathrm{Re}$ \\
$\quad$ to get out of some taxes, it is just as bad as stealing money from the government & 1.90 & Py, reversed \\
I much prefer symmetry to asymmetry & 1.90 & $\mathrm{Ac}$ \\
I certainly feel useless at times & 2.19 & $\mathrm{Sa}, \mathrm{Ac}, \mathrm{Py}$ \\
My daily life is full of things that keep me interested & 2.19 & $\mathrm{Cm}$, Wb \\
Anyone who is able and willing to work hard has a good chance of succeeding & 2.20 & $\mathrm{Not}$ scored \\
I believe women should have as much sexual freedom as men & 2.24 & Ac \\
I have a very strong desire to be a success in the world & 2.30 & Sy \\
\hline
\end{tabular}

a Cs, capacity for status; Re, responsibility; Py, psychological mindedness; Ac, achievement via conformance; $\mathrm{Sa}$, self-acceptance; Cm, communality; Sy, sociability; Wb, well-being.

Table 2

Average item ego-syntonicity (ES) values across CPI folk concept scales

\begin{tabular}{lll}
\hline CPI scale & ES mean & ES SD \\
\hline Dominance & 2.02 & .04 \\
Capacity for status & 2.01 & .06 \\
Sociability & 2.04 & .07 \\
Social presence & 2.04 & .05 \\
Self-acceptance & 2.04 & .05 \\
Independence & 2.04 & .05 \\
Empathy & 2.03 & .04 \\
Responsibility & 2.02 & .06 \\
Socialization & 2.02 & .05 \\
Self-control & 2.04 & .04 \\
Good impression & 2.02 & .05 \\
Communality & 2.06 & .06 \\
Well-being & 2.02 & .05 \\
Tolerance & 2.01 & .03 \\
Achievement via conformance & 2.04 & .07 \\
Achievement via independence & 2.02 & .05 \\
Intellectual efficiency & 2.02 & .05 \\
Psychological mindedness & 2.01 & .06 \\
Flexibility & 2.04 & .05 \\
Femininity/masculinity & 2.04 & .05 \\
\hline
\end{tabular}

with high social desirability and endorsement frequency. Items previously rated as ambiguous and containing negatives (words such as not and prefixes such as un-) were low in ego-syntonicity. Ego-syntonicity was also higher for items whose endorsement was previously judged (McCrae, Costa, \& Piedmont, 1993) to indicate extraversion, conscientiousness, low neuroticism, or openness to experience. Perhaps most importantly, higher levels of ego syntonicity were associated with item validity, defined in Johnson's (2004) study as an item's correlation with a relevant peer rating of personality. 
Table 3

Correlates of item ego-syntonicity

Item property

Correlation with

(Johnson, 2004) ego-syntonicity

Social desirability $.38^{* * *}$

Desirability extremity

Endorsement frequency

Ambiguity indices

Likert ratings

Balanced endorsement

AMBDEX

$-.04$

$-.04$

Linguistic variables

Item length

Direct negatives

Implicit negatives

$-.01$

Negative qualifiers

$-.11^{*}$

Total negatives

$-.08$

Frequency qualifiers

$-.05$

$-.14^{* *}$

.00

Content type

Specific behavior

Behavioral trait

Psychological reaction

Psychological trait

$-.07$

Physiological reaction

$-.06$

Biographical fact

.04

Attitude/opinion

Trait indicativity - professional ratings

Extraversion

Agreeableness

Conscientiousness

Neuroticism

Openness to experience

Trait indicativity - lay category judgments

Social assertiveness

Empathy

Conventionality

Emotional maturity

Intelligence-imagination

$-.09$

Serial position

$-.01$

Item validity

\footnotetext{
${ }^{*} p<.05$ (two-tailed).

** $p<.01$ (two-tailed).

${ }^{* * *} p<.001$ (two-tailed).
}

\subsection{Correlates of disliking and enjoying responding to CPI items}

The mean number of disliked CPI items was $22.3(S D=52.2)$ and the mean number of liked items was $34.9(S D=87.3)$. Correlations between the standard CPI folk concept scales and the total number of disliked and liked items are presented in Table 4. The total number of liked items showed no significant correlations with the standard CPI scales. On 
Table 4

Personality correlates of the number of disliked and liked items

\begin{tabular}{llr}
\hline CPI scale & Disliked & Liked \\
\hline Dominance & -.16 & .13 \\
Capacity for status & $-.26^{*}$ & .15 \\
Sociability & $-.32^{* *}$ & .05 \\
Social presence & -.22 & -.04 \\
Self-acceptance & $-.31^{* *}$ & .01 \\
Independence & -.16 & .07 \\
Empathy & $-.27^{*}$ & .03 \\
Responsibility & -.11 & .20 \\
Socialization & -.06 & .15 \\
Self-control & .04 & .15 \\
Good impression & -.10 & .21 \\
Communality & -.10 & .15 \\
Well-being & -.15 & .15 \\
Tolerance & -.16 & .13 \\
Achievement via conformance & -.13 & .09 \\
Achievement via independence & -.21 & .00 \\
Intellectual efficiency & $-.27^{*}$ & .11 \\
Psychological mindedness & -.16 & .13 \\
Flexibility & -.01 & .11 \\
Femininity/masculinity & $.24^{*}$ & .02 \\
\hline
\end{tabular}

${ }^{*} p<.05$ (two-tailed).

** $p<.01$ (two-tailed).

the other hand, the total number of disliked items showed a clear pattern of negative correlations with what Gough and Bradley (1996, p. 12) refer to as scales measuring "poise, selfassurance, and interpersonal proclivities." People how score low on this cluster of scales (dominance, capacity for status, sociability, social presence, self-acceptance, independence, and empathy) tend to be "private, insulated, and they do not go out of their way to interface with others" (McAllister, 1986, p. 34). The number of disliked items also showed a significant negative correlation with intellectual efficiency (Ie) and a significant positive correlation with femininity/masculinity (F/M). Low Ie with high F/M can indicate emotional oversensitivity and distress (McAllister, 1986, pp. 22-23).

\section{Discussion}

Item ego-syntonicity was defined as the degree to which responding to a personality item was pleasing to the respondent. The present study clarified several issues surrounding the concept of item ego-syntonicity in the CPI. First, although more than half of the CPI items showed ego-syntonicity ratings above the neutral point of 2 , the average ego-syntonicity value of 2.03 was barely above the neutral point, indicating that Gough was only modestly successful in writing ego-syntonic items. Second, the correlates of ego-syntonicity specified the attributes that make items ego-syntonic. Respondents disliked responding to items whose meanings appeared odd or ambiguous, and to items containing negations and references to negative feelings and situations. Respondents enjoyed responding to items on the communality scale, items with which most people agree. They enjoyed items that referred to positive emotions and attitudes. They liked responding to items for which 
endorsement is counted toward higher levels of extraversion, conscientiousness, emotional stability, and openness to experience - all of which are represented in a socially desirable form on the CPI (Gough, 1987). Ego-syntonic items are not merely enjoyable, however. Highly ego-syntonic items also tend to be more valid than less ego-syntonic items, perhaps because they engage highly valued, cardinal aspects of the self (Allport, 1961).

The effect sizes of ego-syntonicity described here are small, perhaps in part because the range of ego-syntonicity for items on the CPI was restricted to the relatively neutral area. An inventory with a wider range of ego-syntonicity, from items causing intense dislike to items causing ecstasy, might have produced larger effect sizes. The small but statistically significant effects observed here, suggest that ego-syntonicity does make a difference, and that if we were able to author a personality inventory with mostly highly enjoyable items, its validity might surpass existing inventories. How to write highly ego-syntonic items remains a question requiring further research. The available data in this study identified only technical properties of items (e.g., absence of negative wording) that have a tiny impact on ego-syntonicity. Perhaps, if we studied public pronouncements that people make with great relish-bumper stickers, letters to the editor, blog entries on the World Wide Web-we could learn more about statements that people really enjoy endorsing (Johnson \& Hogan, 2006).

The present study also examined the experience of ego-syntonicity as a characteristic of the respondent. Somewhat surprisingly, no consistent correlations were found between the total number of items reported as ego-syntonic and any personality dispositions as measured by the standard CPI scales. However, there was a pattern of personality correlates with the total number of disliked items. Those who reported disliking the greatest number of items appeared to be beset by anxieties about being judged by others and hence tended to keep to themselves. They may have been overly sensitive about how their responses to items would be judged.

An obvious limitation of the present study is the relatively small and homogeneous sample. A larger and more diverse sample would increase our confidence about the robustness and generality of the current findings. Furthermore, with a large enough sample one could undertake a more idiographic series of analyses on the unique sets of ego-syntonic items for each individual. Whereas the current study looked at ego-syntonicity as a characteristic of items for people in general (defined by the mean ego-syntonicity ratings from the entire sample), one could conceivably find interesting individual differences in the kinds of items people experienced as ego-syntonic. These differences, in turn, could impact upon the validity of an individual's scores and even suggest different ways of scoring inventories based upon which items a person experienced as ego-syntonic.

A second caution in interpreting the results of the current study concerns whether to take respondents' ego-syntonicity reports at face value. In other words, when someone reports feeling a surge of pleasure after responding to an item, should we believe that they literally experienced a bit of positive affect? As indicated at the beginning of this article, Freudians such as Meehl question whether we can accept self-reports as veridical accounts of psychological dynamics. Others would note that, in addition to self-deception, people might tell us what they think we want to hear rather than what is going on inside their head (Paulhus, 1991). At the other end of the spectrum are those who, in the tradition of Gordon Allport, are willing to accept at face value most of what people tell us about themselves (e.g., Wolfe, 1993). Yet another point of view is the symbolic self-presentational view of Hogan (1991, 1996) and Johnson (1997a, 1997b, 2004). This view suggests that it is 
relatively unimportant what a person is literally feeling when they report experiencing a bit of positive affect upon responding to an item. What matters is what the report about affect communicates symbolically about their self-concept. An accurate understanding of the role of self-deception, other-deception, straightforward communication, and symbolic selfpresentation in item response dynamics is essential for determining when item responses are most likely to be valid (Angleitner, John, \& Löhr, 1986; Blaney, 1991) and would also help us to interpret what individuals are actually doing when we ask them to report on their affects.

One final issue requiring clarification by future research concerns the meaning of item responses that apparently cause negative affect. This article has focused on ego-syntonic items, but what about ego-dystonic items (items referring to thoughts or behavior that feel inconsistent with and repugnant to one's view of oneself)? The current study measures egodystonia-syntonia as a continuum, a continuum that is probably restricted and skewed somewhat toward the syntonic end of the spectrum. Under this operationalization, items associated with ego-dystonic feelings have lower social desirability and are less likely to be endorsed. Yet the question of taking ego-syntonia at face value also apply to ego-dystonia. The Freudian concept of reaction formation suggests that people can be unconsciously attracted to what they outwardly despise. Or perhaps respondents are actually experiencing and straightforwardly reporting real negative affect to ego-dystonic items. Research on individuals with socially undesirable identities suggests a third possibility: that claiming negative experiences helps to build a reputation that is in some way adaptive (Emler, 2005).

Emler (2005) uses this third line of reasoning to explain why juvenile delinquents enthusiastically endorse socially undesirable items on personality inventories. He suggests that delinquents, by consistently presenting themselves (both on personality inventories and in real life) as tough, dangerous, and cruel, are better able to keep potential enemies (including authority figures) at bay. Are individuals who similarly report negative affect when responding to personality items building a reputation that somehow works to their advantage (Watson \& Andrews, 2002)? Does some sort of auto-Schadenfreude underlie these respondents' reports? The current study, by asking respondents to tell us whether they experience negative or position affect after responding to items, opens a door to give us a glimpse of the dynamics underlying responses to personality items. Clearly, further research is needed on the veridicality of these reports and how they are related to identity and reputation.

\section{References}

Allport, G. W. (1961). Pattern and growth in personality. New York: Holt, Rinehart and Winston.

Angleitner, A., John, O. P., \& Löhr, F.-J. (1986). It's what you ask and how you ask it: An itemmetric analysis of personality questionnaires. In A. Angleitner \& J. S. Wiggins (Eds.), Personality assessment via questionnaires (pp. 61-108). New York: Springer-Verlag.

Blaney, P. H. (1991). Not personality scales, personality items. In D. Cicchetti \& W. M. Grove (Eds.), Thinking clearly about psychology: Essays in honor of Paul Meehl, Vol. 2, Personality and psychopathology (pp. 54-70). Minneapolis, MN: University of Minnesota Press.

Buchwald, A. M. (1961). Verbal utterances as data. In H. Feigl \& G. Maxwell (Eds.), Current issues in the philosophy of science: Symposia of scientists and philosophers (pp. 461-472). New York: Holt, Rinehart and Winston.

Emler, N. (2005). Moral character. In V. A. Derlega, B. A. Winstead, \& W. H. Jones (Eds.), Personality: Contemporary theory and research (3rd ed., pp. 392-419). Belmont, CA: Thomson Wadsworth.

Gough, H. G. (1965). Conceptual analysis of psychological test scores and other diagnostic variables. Journal of Abnormal Psychology, 70, 294-320. 
Gough, H. G. (1987). CPI administrator's guide. Palo Alto, CA: Consulting Psychologists Press.

Gough, H. G., \& Bradley, P. (1996). CPI manual (3rd ed.). Palo Alto, CA: Consulting Psychologists Press.

Gruba-McCallister, F. P., \& Rychlak, J. F. (1981). A logical learning theory explanation of why personality scales predict behavior. Journal of Personality Assessment, 45, 494-504.

Hogan, R. (1991). Personality and personality measurement. In M. D. Dunnette \& L. M. Hough (Eds.), Handbook of industrial and organizational psychology (Vol. 2, 2nd ed., pp. 873-919). Palo Alto, CA: Consulting Psychologists Press.

Hogan, R. (1996). A socioanalytic perspective on the five-factor model. In J. S. Wiggins (Ed.), The five-factor model of personality: Theoretical perspectives. New York: Guilford Press.

Johnson, J. A. (1981). The "self-disclosure" and "self-presentation" views of item response dynamics and personality scale validity. Journal of Personality and Social Psychology, 40, 761-769.

Johnson, J. A. (1997a). Seven social performance scales for the California Psychological Inventory. Human Performance, $10,1-30$.

Johnson, J. A. (1997b). Units of analysis for description and explanation in psychology. In R. Hogan, J. A. Johnson, \& S. R. Briggs (Eds.), Handbook of personality psychology (pp. 73-93). San Diego, CA: Academic Press.

Johnson, J. A. (2004). The impact of item characteristics on item and scale validity. Multivariate Behavioral Research, 39, 273-302.

Johnson, J. A. \& Hogan, R. (2006). A socioanalytic view of faking. In R. Griffith (Ed.), A closer examination of applicant faking behavior. Greenwich, CT: Information Age Publishing.

McAllister, L. W. (1986). A practical guide to CPI interpretation. Palo Alto, CA: Consulting Psychologists Press.

McCrae, R. R., Costa, P. T., Jr., \& Piedmont, R. L. (1993). Folk concepts, natural language, and psychological constructs: The California Psychological Inventory and the five-factor model. Journal of Personality, $61,1-26$.

Meehl, P. E. (1945). The dynamics of "structured" personality tests. Journal of Clinical Psychology, 1, $296-303$.

Meehl, P. E. (1978). Theoretical risks and tabular asterisks: Sir Karl, Sir Ronald, and the slow progress of soft psychology. Journal of Consulting and Clinical Psychology, 46, 806-814.

Paulhus, D. L. (1991). Measurement and control of response bias. In J. P. Robinson, P. R. Shaver, \& L. S. Wrightsman (Eds.), Measures of personality and social psychological attitudes (pp. 17-59). New York: Academic Press.

Watson, P. J., \& Andrews, P. W. (2002). Toward a revised evolutionary adaptationist analysis of depression: The social navigation hypothesis. Journal of Affective Disorders, 72, 1-14.

Wolfe, R. N. (1993). A commonsense approach to personality measurement. In K. H. Craik, R. Hogan, \& R. N. Wolfe (Eds.), Fifty years of personality psychology (pp. 269-290). New York: Plenum.

Zuckerman, M., Bernieri, F., Koestner, R., \& Rosenthal, R. (1989). To predict some of the people some of the time: In search of moderators. Journal of Personality and Social Psychology, 57, 279-293. 